\title{
Comparison of the Amount of Temperature Rise in the Pulp Chamber of Teeth Treated With QTH, Second and Third Generation LED Light Curing Units: An In Vitro Study
}

\author{
Rajesh Harivadanbhai Mahant ${ }^{*}$, Shraddha Chokshi ${ }^{2}$, Rupal Vaidya², Pruthvi Patel ${ }^{2}$, Asima Vora ${ }^{2}$, Priyanka \\ Mahant $^{2}$
}

${ }^{1}$ Manubhai Patel Dental College and Oral Research, Bhavnagar University, India

${ }^{2}$ Ahmedabad Dental College and Hospital, Gujarat University, Ahmedabad, Gujarat, India

\author{
*Correspondence to \\ Rajesh Harivadanbhai Mahant, DDS \\ Manubhai Patel Dental College \\ and Oral Research, Bhavnagar \\ University, India. \\ Tel: +91-9033060056; \\ Fax: + 91-2652330362 \\ Email: rhmahant@gmail.com
}

Published online 18 July 2016

\begin{abstract}
Introduction: This in vitro study was designed to measure and compare the amount of temperature rise in the pulp chamber of the teeth exposed to different light curing units (LCU), which are being used for curing composite restorations.

Methods: The study was performed in two settings; first, an in vitro and second was mimicking an in vivo situation. In the first setup of the study, three groups were formed according to the respective three light curing sources. i.e. quartz-tungsten-halogen (QTH) unit and two light-emitting diode (LED) units (second and third generations). In the in vitro setting, direct thermal emission from three light sources at $3 \mathrm{~mm}$ and $6 \mathrm{~mm}$ distances, was measured with a k-type thermocouple, and connected to a digital thermometer. For a simulation of an in vivo situation, 30 premolar teeth were used. Class I Occlusal cavity of all the teeth were prepared and they were restored with incremental curing of composite, after bonding agent application. While curing the bonding agent and composite in layers, the intrapulpal temperature rise was simultaneously measured with a k-type thermocouple. Results: The first setting of the study showed that the heat produced by irradiation with LCU was significantly less at $6 \mathrm{~mm}$ distance when compared to $3 \mathrm{~mm}$ distance. The second setting of the study showed that the rise of intrapulpal temperature was significantly less with third generation LED light cure units than with second generation LED and QTH light cure units.

Conclusion: As the distance from the light source increases, less irradiation heat is produced. Third generation LED lights cause the least temperature change in the pulp chamber of single rooted teeth.

Keywords: pulp chambers; LED dental curing lights; temperature; intrapulpal temperature rise; LED lights; QTH units; third generation LED lights
\end{abstract}

\section{Introduction}

Curing lights have become an indispensable tool in dentistry. Many dental materials are polymerized by them, including direct composite materials, bonding materials, luting materials for inlays and crowns, fissure sealants, bonding materials for orthodontic brackets and so on. An increase in demand for esthetic dental restorations has led to an increase in the use of light sources to photocure resin composites.

Conventional quartz-tungsten-halogen (QTH) curing light is subjected to produce a broad-spectrum light energy, including the infrared radiation range, which is responsible for excessive heat generation. ${ }^{1-3}$ In a classic in vivo study by Zach and Cohen, ${ }^{4}$ an intra-pulpal tempera- ture rise above $5.5^{\circ} \mathrm{C}$ was observed to cause necrosis of dental pulp organs.

In recent years, technologies such as the light-emitting diode (LED) and plasma arc curing lights (PAC) have been introduced as alternatives to conventional light curing units (LCU). Among them, LED seem to be the most efficient technology for several reasons: their narrower spectrum is better centered on the peak of absorption of the main composite photoinitiator, camphorquinone (CQ), and, the low power consumption of LED LCU. ${ }^{5}$

LED LCUs can be classified into "generations" based on successive improvements of their design. ${ }^{6}$ First-generation LED units consist of an array of relatively low-powered chips. Because of their design, they offer low output

Please cite this article as follows: Mahant $\mathrm{RH}$, Chokshi S, Vaidya R, Patel P, Vora A, Mahant P. comparison of the amount of temperature rise in the pulp chamber of teeth treated with QTH, second and third generation LED light curing units: an in vitro study. I Lasers Med Sci. 2016;7(3):184-191. doi:10.15171/jlms.2016.32. 
and poor curing performance compared with conventional QTH lights. First-generation LED lights generally require much longer exposure times to provide a similar level of curing performance as QTH lights, and they generate less temperature in their targets. First-generation LED LCUs display an average irradiance of $150-400 \mathrm{~mW} /$ $\mathrm{cm}^{2}$ and a power output of $1 \mathrm{~W}$.

By utilizing a single chip of much higher surface area, which emits only one color range of greatly increased output power, second-generation LED models perform better than their first-generation counterparts. ${ }^{6}$ Second-generation LED LCUs can achieve similar polymerization and curing performances to those produced by QTH lights under similar exposure times. ${ }^{7}$ Second-generation LED LCUs display an irradiance of up to $800 \mathrm{~mW} / \mathrm{cm}^{2}$ and a power output of $5 \mathrm{~W}$.

Third-generation LED lights use a combination of LEDs to produce a broader spectral output. These lights may polymerize a broader range of resins than the second-generation curing lights. ${ }^{6}$ The irradiance and power output of third-generation LED LCUs exceed $1.100 \mathrm{~mW} / \mathrm{cm}^{2}$ and 8 W, respectively. ${ }^{6}$

Recently, bleached shades of composites have been developed to match lighter shades of teeth which contain alternative initiators to avoid the intense yellow color of camphorquinone. For this reason, as well as to improve photoinitiation efficiency, alternative photoinitiators, such as phenylpropanedione (PPD), monoacylphosphine oxide (MAPO or Lucirin TPO) and bisacylphosphine oxide (BAPO or Irgacure 819), have been introduced into composites. However, the absorption spectra of these molecules are different from the camphorquinone spectrum. To overcome this problem, the so-called third generation of LED LCU was invented, combining two different light peaks, blue and violet. ${ }^{5}$ Initial results achieved with these lights have been promising; being similar to or better than those achieved with second generation LED LCU.

Asmussen and Peutzfeldt concluded that temperature rise was correlated with power density. ${ }^{7}$ The power densities of the third generation LED lights are higher than those of QTH lights, so the temperature rise in the pulp chamber can be higher with these lights.

The aim of this study was to evaluate the direct thermal emission and increase in intrapulpal temperature generated by QTH and LED LCU. Null hypotheses for this study are that the distance between light source and tooth does not affect the temperature and QTH and second and third generation LED lights increase the pulp chamber temperature in the same amount.

\section{Methods}

This in vitro study was done in 2 parts:

The first part of the study was undertaken to directly quantify the thermal emission from halogen and LED LCUs.

The second part was an in vivo simulation of composite restoration, which compared the temperature rise in pulp chamber of human mandibular first premolar with photoactivation from different LCU.

Directly Quantify the Thermal Emission From Halogen and LED LCUs: In Vitro Study (First Part of the Study)

Three groups were formed according to the light curing unit used (Table 1).

In this study, the exposure time protocol for all three LCU was followed according to a study by Leprince et al. ${ }^{5}$ One acrylic base plate ( $30 \mathrm{~mm}$ X $30 \mathrm{~mm}$ X $6 \mathrm{~mm}$ ) was made with a groove $(15 \mathrm{~mm} \mathrm{X} 1.5 \mathrm{~mm})$ on its top to receive $\mathrm{K}$ type thermocouple. ${ }^{8}$ The thermocouple was secured onto the groove so that its surface it was flushed against the top of the base plate (Figure 1).

Four acrylic spacer plates (Figure 2) (dimension of spacer plates are mentioned in Table 2) were made to control the distance between the thermocouple and LCU tip (i.e. $3 \mathrm{~mm} 6 \mathrm{~mm}$ distance) (Figure 3). A window was made in each spacer according to the respected tip diameter of LCU. According to each group, a particular acrylic spacer was kept between the tip of the curing light and the acrylic block which had secured thermocouple in it (Figure 4). The light guide tips of the various LCUs were placed over the window of the acrylic spacer and activated (Figure 4). The thermal emission of each light curing unit was measured by a K-type thermocouple (Anjaney Thermocontrols) and a digital thermometer (accurate to $0.18^{\circ} \mathrm{C}$, with 0.1-second response time) (Anjaney Thermocontrols, Ahmedabad, India). The study was done at $30^{\circ} \mathrm{C}$ room temperature. Five readings were obtained for each of the light-curing units (Figure 5; Tables 3 and 4).

Data was subjected to one-way analysis of variance (ANOVA)/Scheffe post-hoc test at significance level of 0.05 . The mean values of maximum temperature rise caused by different LCUs were compared. Statistical analysis was performed using the data analysis SPSS statistical software program (version 17.0, SPSS Inc., Chicago, IL, USA).

Mimicking In Vivo Situation of Composite Resin Restoration

Thirty non-carious and crack free human mandibular first premolar teeth (single canal) were prepared for class

Table 1. Study Groups

\begin{tabular}{|c|c|c|c|c|}
\hline \multirow{2}{*}{ Group no. } & \multirow{2}{*}{ Light Curing Unit Used } & \multirow{2}{*}{ Diameter of the Tip of LCU } & \multicolumn{2}{|c|}{ Recommended Time to Cure (s) } \\
\hline & & & For Dentin Bonding Agent & For Composite \\
\hline 1 & QHL75 halogen lights (Dentsply) & $7 \mathrm{~mm}$ & 20 & 40 \\
\hline II & $\begin{array}{l}\text { Cure master } 2^{\text {nd }} \text { generation LED light } \\
\text { (Confident, NSK) }\end{array}$ & $7 \mathrm{~mm}$ & 20 & 40 \\
\hline III & $\begin{array}{l}\text { Bluephase } 20 \mathrm{i} 3^{\text {rd }} \text { generation LED light } \\
\text { (Ivoclar Vivadent) }\end{array}$ & $10 \mathrm{~mm}$ & $10^{*}$ & $20^{*}$ \\
\hline
\end{tabular}




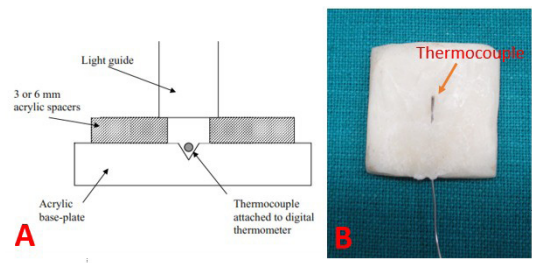

Figure 1. A) Schematic Diagram of Experimental Set-up. B) Thermocouple Secured in Acrylic Block.

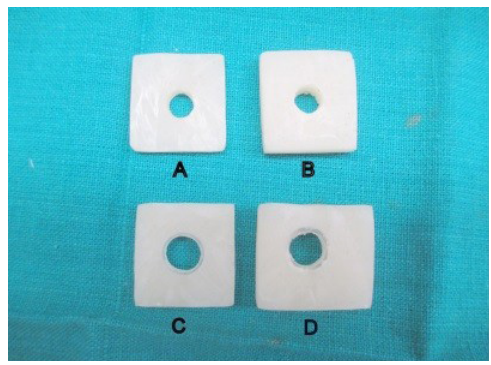

Figure 2. Acrylic Spacers.

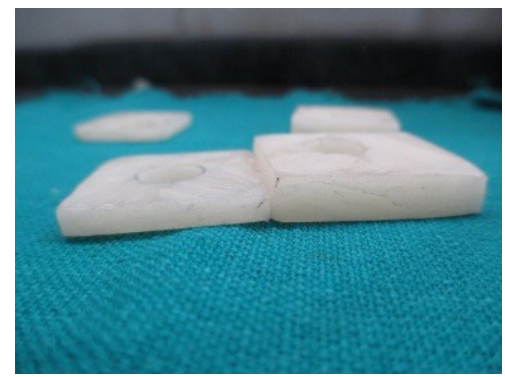

Figure 3. Spacer of $3 \mathrm{~mm}$ and $6 \mathrm{~mm}$ Thickness.

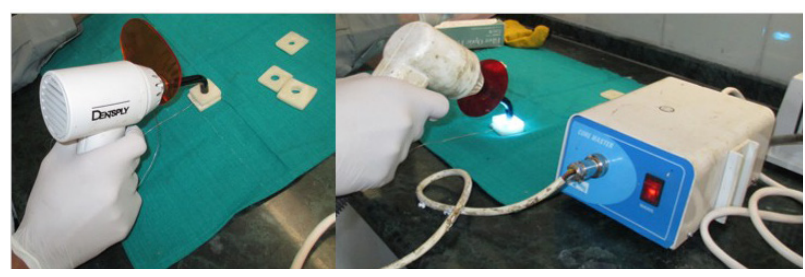

Figure 4. Experimental Procedure.

Table 2. Dimensions of Acrylic Spacers

\begin{tabular}{lccc}
\hline Spacer No. & $\begin{array}{c}\text { Dimension } \\
(\mathbf{m m})\end{array}$ & $\begin{array}{c}\text { Window } \\
(\mathbf{m m})\end{array}$ & $\begin{array}{c}\text { Group No. Which Have } \\
\text { Used Spacer }\end{array}$ \\
\hline $\mathrm{A}$ & $30 \times 30 \times 3$ & 7 & I \& II \\
B & $30 \times 30 \times 6$ & 7 & I \& II \\
C & $30 \times 30 \times 3$ & 10 & III \\
D & $30 \times 30 \times 6$ & 10 & III \\
\hline
\end{tabular}

I occlusal composite restoration with the following specifications: $2 \mathrm{~mm}$ width, $5 \mathrm{~mm}$ length and $3 \mathrm{~mm}$ depth. To measure the temperature rise in pulp chamber while curing, a thermocouple was inserted in the pulp chamber.

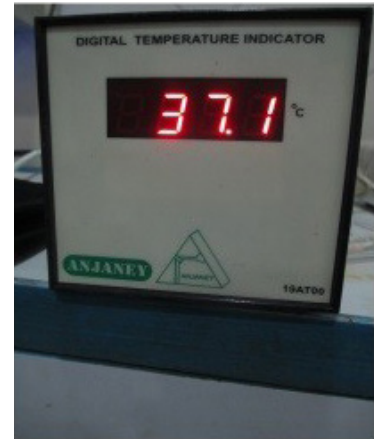

Figure 5. Digital Thermometer Showing Temperature During First Setting of the Study.

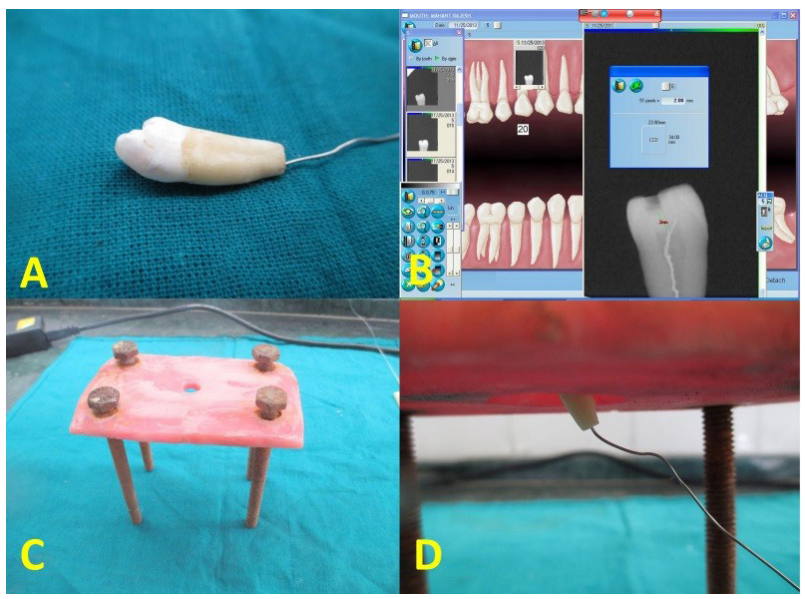

Figure 6. (A) Thermocouple in Tooth. (B) Radiographic Confirmation of Thermocouple. (C) Tooth Suspension Platform. (D) Figure Showing Suspension of the Tooth Through Platform.

The $3 \mathrm{~mm}$ apical portion of the root of each tooth was cut and the pulpal tissues were removed with the help of $\mathrm{K}$ files. The pulp chamber and root canal were then cleaned with a $5.25 \%$ sodium hypochlorite solution (Vishal Dentocare) and finally flushed with distilled water and then dried with paper points.

Before inserting the thermocouple, an electrocardiogram (ECG) gel (to facilitate the transfer of heat from the walls of the pulp chamber to the thermocouple) was injected into the pulp chamber through the prepared apical portion of the root, for surrounding and stabilizing the thermal probe in position. (ECG gel is a water based gel and the pulp's main component is also water, so ECG gel was used to mimic heat transfer of pulpal tissue.) The thermocouple, connected to a digital thermometer (the same which was used in the first part of the study) passed through the apex (Figure 6D) and was then placed into the pulp chamber, touching the central region of the chamber's roof. The root end was sealed with cyanoacrylate glue (Araldite) (Figure 6A). The position of the thermocouple was confirmed with the radiovisiograph. (Figure 6B) Only those teeth, with the remaining dentin thickness of $2 \mathrm{~mm}$, were included in the present study. The teeth were randomly divided into three groups (10 in each) according to allo- 
Table 3. Temperature Noted After Estimated Time for Curing the Dentin Bonding Agent and the Composite at $3 \mathrm{Mm}$ and $6 \mathrm{Mm}$ Distance From the Tip of the Light Curing Unit ${ }^{a}$

\begin{tabular}{|c|c|c|c|c|c|}
\hline \multirow{3}{*}{ LCU } & \multicolumn{5}{|c|}{ Temperature Increase $\left({ }^{\circ} \mathrm{C}\right)$ After Estimated Time Taken to Cure $(\text { Mean } \pm \mathrm{SD})^{\mathrm{b}}$} \\
\hline & \multirow{2}{*}{ Sr. No. } & \multicolumn{2}{|c|}{ The Dentin Bonding Agent } & \multicolumn{2}{|c|}{ The Composite } \\
\hline & & At $3 \mathrm{~mm}$ Distance & At $6 \mathrm{~mm}$ Distance & At $3 \mathrm{~mm}$ Distance & At $6 \mathrm{~mm}$ Distance \\
\hline \multirow{5}{*}{ QHL75 } & 1 & $34.8(+4.8)$ & $32.8(+2.8)$ & $37.2(+7.2)$ & $34.0(+4.0)$ \\
\hline & 2 & $34.5(+4.5)$ & $32.6(+2.6)$ & $37.0(+7.0)$ & $33.8(+3.8)$ \\
\hline & 3 & $34.8(+4.8)$ & $32.7(+2.7)$ & $37.1(+7.1)$ & $34.0(+4.0)$ \\
\hline & 4 & $34.6(+4.6)$ & $32.6(+2.6)$ & $37.2(+7.2)$ & $33.9(+3.9)$ \\
\hline & 5 & $34.8(+4.8)$ & $32.8(+2.8)$ & $37.1(+7.1)$ & $34.1(+4.1)$ \\
\hline \multirow{5}{*}{ CURE MASTER } & 1 & $32.8(+2.8)$ & $32.0(+2.0)$ & $34.8(+4.8)$ & $33.8(+3.8)$ \\
\hline & 2 & $32.7(+2.7)$ & $31.9(+1.9)$ & $34.8(+4.8)$ & $33.5(+3.5)$ \\
\hline & 3 & $32.5(+2.5)$ & $31.9(+1.9)$ & $34.6(+4.6)$ & $33.7(+3.7)$ \\
\hline & 4 & $32.8(+2.8)$ & $32.0(+2.0)$ & $34.7(+4.7)$ & $33.9(+3.9)$ \\
\hline & 5 & $32.7(+2.7)$ & $32.0(+2.0)$ & $34.7(+4.7)$ & $33.7(+3.7)$ \\
\hline \multirow{5}{*}{ Bluephase 20i } & 1 & $31.8(+1.8)$ & $31.0(+1.0)$ & $32.5(+2.5)$ & $31.8(+1.8)$ \\
\hline & 2 & $31.9(+1.9)$ & $31.1(+1.1)$ & $32.5(+2.5)$ & $31.8(+1.8)$ \\
\hline & 3 & $31.7(+1.7)$ & $31.1(+1.1)$ & $32.4(+2.4)$ & $31.9(+1.9)$ \\
\hline & 4 & $31.7(+1.7)$ & $30.9(+0.9)$ & $32.4(+2.4)$ & $31.8(+1.8)$ \\
\hline & 5 & $31.8(+1.8)$ & $31.0(+1.0)$ & $32.4(+2.4)$ & $31.9(+1.9)$ \\
\hline
\end{tabular}

a Baseline temperature was $30^{\circ} \mathrm{C}$.

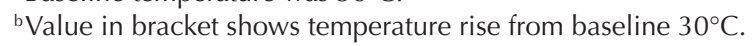

Table 4. Mean Temperature Rise After Curing the Dentin Bonding Agent and the Composite at $3 \mathrm{~mm}$ and $6 \mathrm{~mm}$ Distance From the Tip of Light Curing Unit

\begin{tabular}{|c|c|c|c|c|c|}
\hline \multirow{3}{*}{ LCU } & \multicolumn{4}{|c|}{ Mean Temperature Increase $\left({ }^{\circ} \mathrm{C}\right)($ Mean $\pm \mathrm{SD})$ for Estimated Time Taken to Cure } & \multirow{3}{*}{$P$ Value } \\
\hline & \multicolumn{2}{|c|}{ The Dentin Bonding Agent } & \multicolumn{2}{|c|}{ The Composite } & \\
\hline & At $3 \mathrm{~mm}$ Distance & At $6 \mathrm{~mm}$ Distance & At $3 \mathrm{~mm}$ Distance & At $6 \mathrm{~mm}$ Distance & \\
\hline QHL75 & $4.70 \pm 0.14$ & $2.70 \pm 0.10$ & $7.12 \pm 0.08$ & $3.96 \pm 0.11$ & $0.000^{\mathrm{a}}$ \\
\hline CURE MASTER & $2.70 \pm 0.12$ & $1.96 \pm 0.05$ & $4.72 \pm 0.08$ & $3.72 \pm 0.15$ & $0.000^{\mathrm{a}}$ \\
\hline Bluephase 20i & $1.78 \pm 0.08$ & $1.02 \pm 0.08$ & $2.44 \pm 0.05$ & $1.84 \pm 0.05$ & $0.000^{\mathrm{a}}$ \\
\hline
\end{tabular}

a The mean temperature increase is significant as the $P<0.001$ level.

cation of each light curing unit (Table 1).

This whole assembly of tooth with thermocouple was submerged into water of the waterbath machine up to the cemento-enamel junction of the tooth (like attachment of periodontal ligament) with the help of custom made - acrylic platform (Figures 7, 8, and 6C). In the lab, waterbath machine was used to keep water at a constant temperature of a determined $37^{\circ} \mathrm{C}$ (i.e. to simulate human body temperature). The tooth preparation was etched with $37 \%$ phosphoric acid gel (D-Tech, Sakhi Chem,PVTltd ) for 15 seconds, which was rinsed by air/water spray for 40 seconds. One coat of adhesive Tetric N-Bond (Ivoclar Vivadent) (2 step etch-and-rinse) was applied on all walls of the teeth preparation. Data recording was initiated, and when a stable, physiologic baseline temperature $\left(37^{\circ} \mathrm{C}\right)$ of water (into which the teeth were submerged) was reached, the light curing unit was activated for the specified duration, and temperature rise during this period was recorded (Figure 9). ${ }^{9}$ Then incremental curing of $1 \mathrm{~mm}$ photocurable composite was done up to $3 \mathrm{~mm}$. Each increment was cured and temperature rise was noted for each incremental curing (Figure 10, Table 5). The composite was placed with incremental layering technique. Sequential placement of composite did not permit the material to return to its initial temperature. ${ }^{10}$ Hence, a break of 30 seconds was allowed between each increment to allow the dissipation of the heat. The light curing tip of each unit was held the nearest to the tooth surface. The results were tabulated and statistically analyzed by ANOVA test and

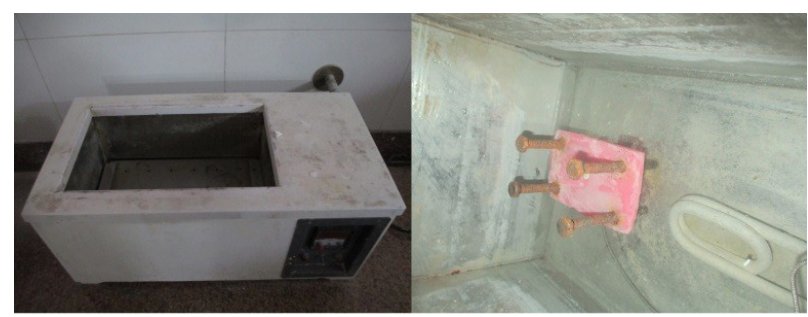

Figure 7. Waterbath Equipment for Controlled Water Temperature.

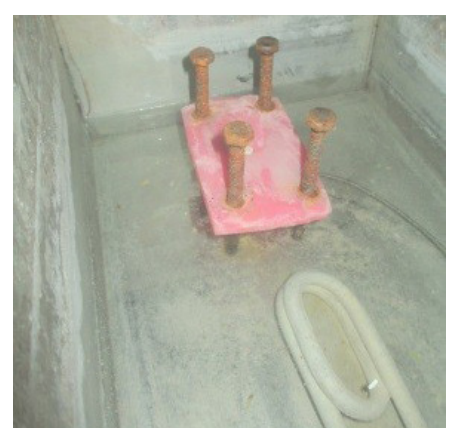

Figure 8. Platform in the Waterbath. 


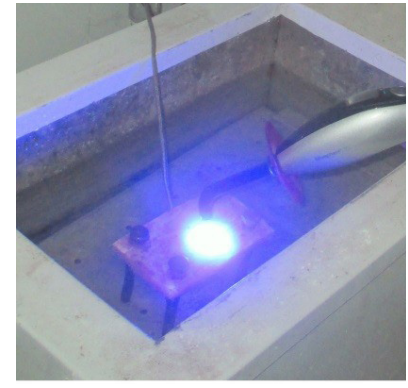

Figure 9. Activation of Light Curing Unit on the Restoration of the Tooth.

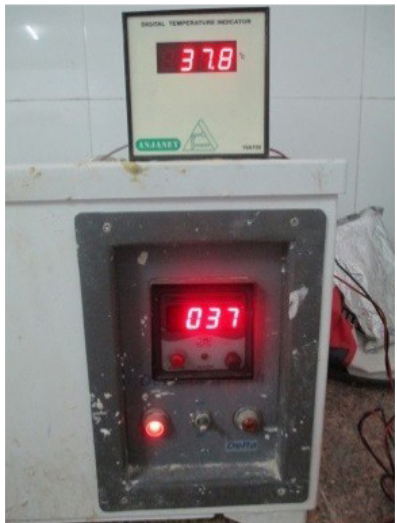

Figure 10. Digital Thermometer (connected with thermocouple) is kept over waterbath, showing intrapulpal temperature change.

Tukey HSD test.

When one way ANOVA test was applied, statistically significant difference was found in temperature rise at both the distance between the light curing unit and the thermocouple. The temperature rise observed at $3 \mathrm{~mm}$ distance was significantly higher than at $6 \mathrm{~mm}$ distance. These results concurred with those of Shortall and Harrington. ${ }^{11}$ In addition, the thermal emission of LED lights was significantly lower than halogen light (QHL75) at 3 $\mathrm{mm}$ and $6 \mathrm{~mm}$ distances (Table 3, Figure 11). Among the LED lights, the newer third generation LED light (Bluephase 20i) had showed significantly less temperature rise than second generation LED light (CURE MASTER).

With all the LCU, the rate of increase in intrapulpal temperature sequentially decreases during the curing of the first, the second and the third layer of composite (Table 6). The intrapulpal temperature increase during the curing of bonding agent is lower than that which occurs during the

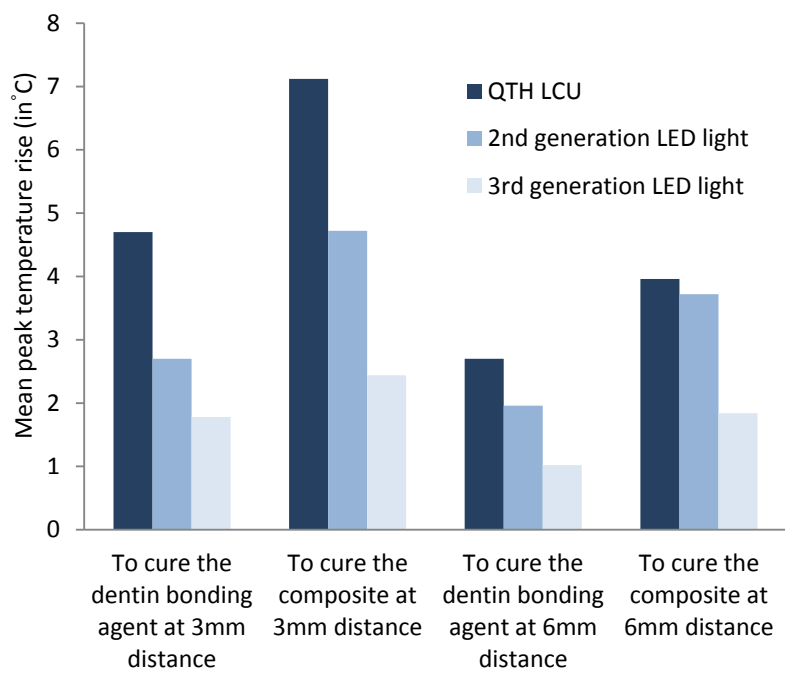

Figure 11. Mean Peak Temperature Rise After the Time Taken to Cure the Dentin Bonding Agent and the Composite (in ${ }^{\circ} \mathrm{C}$ ) at 3 $\mathrm{mm}$ and $6 \mathrm{~mm}$ Distance From the Tip of Light Curing Unit.

curing of the first layer of composite. (Distance increases after application of composite) (Table 6, Figure 12).

While comparing intrapulpal temperature rise during curing of the bonding agent and first, second and third increment it was apparent from Figure 12 that, Bluephase $20 \mathrm{i}$ had shown the least temperature rise followed by CURE MASTER (second generation LED light), QHL75 (QTH light).

\section{Discussion}

The heat generated in the tooth during light curing of composite resin results in an increase in intrapulpal temperature. Zach and Cohen ${ }^{4}$ studied the teeth of Rhesus monkeys. In that study when the temperature of pulp was increased by $5.5^{\circ} \mathrm{C}, 15 \%$ of the teeth became necrotic. So the pulp temperature rise should be kept as low as possible while curing the composite to avoid damaging the pulp. It has been stated that the main influencing factor for temperature rise, during the light-activated polymerization of composites, is the energy emitted from the LCU; and the exothermic composite polymerization process is only of secondary importance to the temperature rise., ${ }^{2,12}$

The first part of our study was designed according to the study done by Yap and Soh. ${ }^{13}$ it is apparent that as the distance between light curing unit and the tooth decreases, the temperature tends to rise. The decrease in light intensity of the LCU was in conformity with the inverse square

Table 5. Mean Intrapulpal Temperature Rise (in ${ }^{\circ} \mathrm{C}$ ) Associated With Different LCU During the Curing of Composite Restorations in the Class I Tooth Preparations

\begin{tabular}{lcccc}
\hline \multirow{2}{*}{ LCU } & \multicolumn{4}{c}{ Temperature Increase (in ${ }^{\circ}$ C) (Mean \pm SD) } \\
\cline { 2 - 5 } & $\begin{array}{c}\text { After Curing of Bonding } \\
\text { Agent }\end{array}$ & $\begin{array}{c}\text { After Curing the 1st } \\
\text { Increment of Composite }\end{array}$ & $\begin{array}{c}\text { After Curing the 2nd } \\
\text { Increment of Composite }\end{array}$ & $\begin{array}{c}\text { After Curing the 3rd } \\
\text { Increment of Composite }\end{array}$ \\
\hline QHL75 & $3.68 \pm 0.10^{\mathrm{a}}$ & $3.92 \pm 0.08^{\mathrm{a}}$ & $3.62 \pm 0.08^{\mathrm{a}}$ & $3.31 \pm 0.09^{\mathrm{a}}$ \\
CURE MASTER & $2.02 \pm 0.10^{\mathrm{a}}$ & $2.18 \pm 0.11^{\mathrm{a}}$ & $1.99 \pm 0.07^{\mathrm{a}}$ & $1.79 \pm 0.07^{\mathrm{a}}$ \\
Bluephase 20i & $1.20 \pm 0.10^{\mathrm{a}}$ & $1.23 \pm 0.07^{\mathrm{a}}$ & $1.00 \pm 0.07^{\mathrm{a}}$ & $0.77 \pm 0.08^{\mathrm{a}}$ \\
\hline
\end{tabular}

${ }^{a}$ The mean temperature increase is highly significant as the $P<0.001$ level. 
Table 6. Intrapulpal Temperature (in ${ }^{\circ} \mathrm{C}$ ) Associated With Different LCU During the Curing of Composite Restorations in the Class I Tooth Preparations $^{\mathrm{a}}$

\begin{tabular}{|c|c|c|c|c|c|}
\hline \multirow{2}{*}{ LCU } & \multirow{2}{*}{ Sample No. } & \multirow{2}{*}{ Curing Dentin Bonding Agent } & \multicolumn{3}{|c|}{ Curing Composite } \\
\hline & & & 1st Increment & 2nd Increment & 3rd Increment \\
\hline \multirow{10}{*}{ QHL75 } & 1 & $40.5(+3.5)$ & $40.8(+3.8)$ & $40.5(+3.5)$ & $40.2(+3.2)$ \\
\hline & 2 & $40.7(+3.7)$ & $40.9(+3.9)$ & $40.6(+3.6)$ & $40.4(+3.4)$ \\
\hline & 3 & $40.8(+3.8)$ & $41.0(+4.0)$ & $40.7(+3.7)$ & $40.3(+3.3)$ \\
\hline & 4 & $40.7(+3.7)$ & $41.0(+4.0)$ & $40.7(+3.7)$ & $40.4(+3.4)$ \\
\hline & 5 & $40.6(+3.6)$ & $40.9(+3.9)$ & $40.6(+3.6)$ & $40.3(+3.3)$ \\
\hline & 6 & $40.7(+3.7)$ & $40.8(+3.8)$ & $40.5(+3.5)$ & $40.2(+3.2)$ \\
\hline & 7 & $40.8(+3.8)$ & $41.0(+4.0)$ & $40.7(+3.7)$ & $40.4(+3.4)$ \\
\hline & 8 & $40.8(+3.8)$ & $41.0(+4.0)$ & $40.6(+3.6)$ & $40.2(+3.2)$ \\
\hline & 9 & $40.6(+3.6)$ & $40.9(+3.9)$ & $40.6(+3.6)$ & $40.3(+3.3)$ \\
\hline & 10 & $40.6(+3.6)$ & $40.9(+3.9)$ & $40.7(+3.7)$ & $40.4(+3.4)$ \\
\hline \multirow{10}{*}{ CURE MASTER } & 1 & $39.0(+2.0)$ & $39.2(+2.2)$ & $39.0(+2.0)$ & $38.8(+1.8)$ \\
\hline & 2 & $39.1(+2.1)$ & $39.3(+2.3)$ & $39.1(+2.1)$ & $38.9(+1.9)$ \\
\hline & 3 & $38.9(+1.9)$ & $39.1(+2.1)$ & $38.9(+1.9)$ & $38.7(+1.7)$ \\
\hline & 4 & $38.9(+1.9)$ & $39.0(+2.0)$ & $38.9(+1.9)$ & $38.8(+1.8)$ \\
\hline & 5 & $39.1(+2.1)$ & $39.2(+2.2)$ & $39.0(+2.0)$ & $38.8(+1.8)$ \\
\hline & 6 & $39.0(+2.0)$ & $39.2(+2.2)$ & $39.0(+2.0)$ & $38.9(+1.9)$ \\
\hline & 7 & $39.1(+2.1)$ & $39.3(+2.3)$ & $39.1(+2.1)$ & $38.8(+1.8)$ \\
\hline & 8 & $39.2(+2.2)$ & $39.3(+2.3)$ & $39.0(+2.0)$ & $38.7(+1.7)$ \\
\hline & 9 & $39.0(+2.0)$ & $39.2(+2.2)$ & $39.0(+2.0)$ & $38.8(+1.8)$ \\
\hline & 10 & $38.9(+1.9)$ & $39.0(+2.0)$ & $38.9(+1.9)$ & $38.7(+1.7)$ \\
\hline \multirow{10}{*}{ Bluephase } & 1 & $38.2(+1.2)$ & $38.3(+1.3)$ & $38.0(+1.0)$ & $37.8(+0.8)$ \\
\hline & 2 & $38.1(+1.1)$ & $38.2(+1.2)$ & $37.9(+0.9)$ & $37.6(+0.6)$ \\
\hline & 3 & $38.3(+1.3)$ & $38.2(+1.2)$ & $38.0(+1.0)$ & $37.8(+0.8)$ \\
\hline & 4 & $38.1(+1.1)$ & $38.1(+1.1)$ & $37.9(+0.9)$ & $37.7(+0.7)$ \\
\hline & 5 & $38.1(+1.1)$ & $38.2(+1.2)$ & $38.0(+1.0)$ & $37.8(+0.8)$ \\
\hline & 6 & $38.2(+1.2)$ & $38.2(+1.2)$ & $38.0(+1.0)$ & $37.7(+0.7)$ \\
\hline & 7 & $38.2(+1.2)$ & $38.3(+1.3)$ & $38.1(+1.1)$ & $37.9(+0.9)$ \\
\hline & 8 & $38.4(+1.4)$ & $38.3(+1.3)$ & $38.0(+1.0)$ & $37.8(+0.8)$ \\
\hline & 9 & $38.3(+1.3)$ & $38.3(+1.3)$ & $38.1(+1.1)$ & $37.8(+0.8)$ \\
\hline & 10 & $38.1(+1.1)$ & $38.2(+1.2)$ & $38.0(+1.0)$ & $37.8(+0.8)$ \\
\hline
\end{tabular}

a Baseline waterbath temperature is $37^{\circ} \mathrm{C}$.

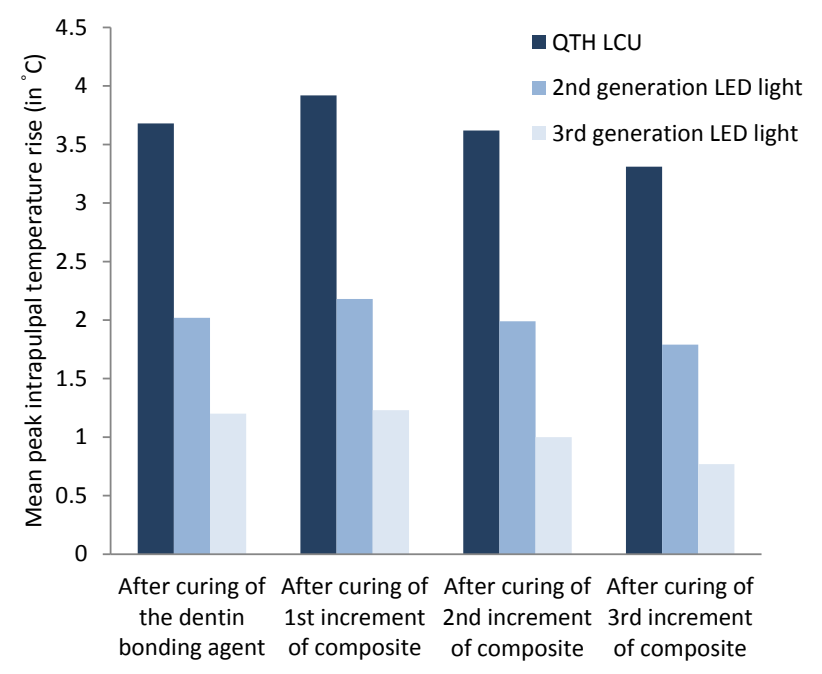

Figure 12. Mean Peak Intrapulpal Temperature Rise (in ${ }^{\circ} \mathrm{C}$ ) Associated With Different LCU During Curing of Composite Restoration in the Class I Tooth Preparation. law for the distances between the tip of the LCU and the surface of the restoration. ${ }^{13-15}$ For QTH light curing unit, at $3 \mathrm{~mm}$ distance, a temperature rise of $4.5-7.2^{\circ} \mathrm{C}$ was recorded. For second and third generation LED devices, the temperature risings recorded at $3 \mathrm{~mm}$ distance were between $2.5-4.8^{\circ} \mathrm{C}$ and $1.7-2.5^{\circ} \mathrm{C}$ respectively. As noted in Table 3, the temperature rise at 6-mm distance was 2.6$4^{\circ} \mathrm{C}$ (for QTH light), $1.9-3.9^{\circ} \mathrm{C}$ (second generation LED light) and $0.9-1.9^{\circ} \mathrm{C}$ (third generation LED light). Hence, as the distance between light curing unit and the tooth decreases, the temperature tends to rise. So our null hypothesis was wrong regarding the distance between the light source and the tooth/ restorative material.

From the result of the present study, it is also obvious that both LED LCUs emit significantly lower heat than QTH lights at both $3 \mathrm{~mm}$ and $6 \mathrm{~mm}$ distances. The reason for less heat emission was the use of a junction of doped semiconductors ( $\mathrm{p}-\mathrm{n}$ junctions) (as in LED light) rather than a hot filament (as in QTH bulbs). As the spectral output of gallium nitride blue LEDs falls within the ab- 
sorption spectrum of the camphorquinone photoinitiators, no light filters are required as in QTH light. ${ }^{10}$

The light intensity of Bluephase $20 \mathrm{i}\left(2000 \mathrm{~mW} / \mathrm{cm}^{2}\right.$, third generation LED light) is considerably higher than that of QHL75 (450 $\mathrm{mW} / \mathrm{cm}^{2}$, QTH light). As concluded in the study conducted by Santini et al, ${ }^{16}$ there is a direct relation between the light intensity and the rise in pulp chamber temperature. But since the third generation LED requires less curing time compared to QTH, LED shows lower temperature rise than QTH light. ${ }^{5,17}$ In addition, there was a narrow spectrum of radiation of higher intensity present in the emitted light by LED lights. This fact has been offered as an explanation for the finding that Bluephase $20 \mathrm{i}$ curing units have resulted in less heat generation than QHL75 curing units.

In the second part of this study, an in vivo simulation of curing of composite restoration with various LCU was performed. The present study was designed exactly according to the study done by Santini et al. ${ }^{16}$

While considering the time, the highest temperature noted in the entire restorative procedure was during the polymerization of the bonding agent because of its proximity to the pulp chamber. This was in accordance with the results found by Millen et al. ${ }^{14}$

Previous study observed that the temperature decreased with increase in thickness of the composite. ${ }^{18}$ As the thickness of composite increases, less heat would be available at the roof of the pulp chamber. But special concern lies for bonding procedures in deep cavities, where photoactivation of the adhesive is carried out without any layer of restorative resin that could act as a barrier for thermal conduction.

In this study, during the placement of the first composite increment, the greatest temperature rise was observed at the base of the cavity. It was observed that with the placement of the second increment of composite, the temperature rise became significantly lower. This indicates the insulating property of composite material. The similar results were obtained in the study by Kavitha et al. ${ }^{19}$ Here, the LED units produced little temperature increase when compared to QTH units. This result was also in accordance with the findings of $\mathrm{McCabe}^{20}$ and Lloyd et al. ${ }^{12}$

While evaluating the in vivo simulation, the sum of all the exposures seems to cause a considerable rise in pulpal temperature. The maximum temperature rise observed was $4.0^{\circ} \mathrm{C}$ for QTH unit, which was well below the limits that affect the integrity of the dental pulp. It is always better to use LED light curing unit rather than QTH units, as LED units cause minimal thermal emission. Our second part of the hypothesis is also wrong, because LED light elicit less temperature, and among them the third generation LED source produces the least pulp chamber temperature rise.

Thermal stimuli can trigger nervous reflexes and release vasoactive mediators resulting in arteriolar dilatation and enhance the blood circulation of the pulp. Blood flow through the pulp tissue causes heat dissipation and some amount of heat may also be absorbed by the gingival con- nective tissues. The experimental set up did not account for blood circulation which occurs in the natural, vital pulp chamber. The experimental values obtained may be higher than those occurring in vivo and cannot be directly applied to temperature changes in vivo.

In this study, we had not taken in account the heat coming from the exothermic reaction which occurs during the polymerization of the composite. Therefore, further in vivo and in vitro investigations are needed to assess the effect of exothermic reaction of resin composites on temperature changes in dentin.

The results of the present study may help the clinicians to develop a better understanding of the possible adverse consequences of their choice of light curing unit. While curing composites in deep cavities, clinicians should be aware of the potential thermal hazard associated with using high intensity lights. Minimum irradiation time should be used, when curing bonding agents. As the heat emitted by LED lights are significantly lower than halogens, they exhibited a potential advantage over halogen lights in the curing of composites.

\section{Conclusion}

According to the results obtained, it was concluded that the LCU induce the temperature rise during the restorative procedure. The heat emitted by different LED/halogen lights varies significantly. As the distance between the light source and the thermocouple increased, the effect of direct thermal emission decreased. From the second setting of the study, it was concluded that the use of low and high intensity light sources did not cause rise in intrapulpal temperature which could exceed the reference values of $5.5^{\circ} \mathrm{C}$ reported to induce pulpal injury. The third generation LED light curing unit had the least heat emission and could induce the lower rise in intrapulpal temperature in pulp chamber of the single rooted tooth.

\section{Conflict of Interests}

The authors declare that they have no conflict of interests.

\section{References}

1. Khounganian R, Ashour M. Scanning electron microscopic study of visible light curing effects on the oral mucous membrane. East Mediterr Health J. 1997;3(3):540-548.

2. Guiraldo RD, Consani S, Lympius T, Schneider LF, Sinhoreti MA, Correr-Sobrinho L. Influence of the light curing unit and thickness of residual dentin on generation of heat during composite photoactivation. J Oral Sci. 2008;50:137-142. doi:10.2334/josnusd.50.137.

3. Santini A. Current status of visible light activation units and the curing of light-activated resin-based composite materials. Dent Update. 2010;37(4):214-216.

4. Zach L, Cohen G. Pulp response to externally applied heat. Oral Surg Oral Med Oral Pathol. 1965;19:515-530. doi:10.1016/0030-4220(65)90015-0.

5. Leprince J, Devaux J, Mullier T. Pulpal-temperature Rise and Polymerization Efficiency of LED Curing Lights. Oper Dent. 2010;35(2):220-230. doi:10.2341/09-203-1.

6. Wahbi M, Aalam F, Fatiny F. Characterization of heat emission of light-curing units. Saudi Dent J. 2012;24(2):91- 
98. doi:10.1016/j.sdentj.2012.01.003.

7. Asmussen E, Peutzfeldt A. Temperature rise induced by some light emitting diode and quartz-tungsten-halogen curing units. Eur J Oral Sci. 2005;113:96-98. doi:10.1111/ j.1600-0722.2004.00181.x.

8. Martins G, Cavalcanti B, Rode S. Increases in intrapulpal temperature during polymerization of composite resin. J Prosthet Dent. 2006;96:328-331. doi:10.1016/j. prosdent.2006.09.008.

9. Busemann I, Lipke C, Schattenberg A. Shortest exposure time possible with LED curing lights. Am J Dent. 2011;24(1):37-44.

10. Nakamura S, Mukai T, Senoh M. Candela-class highbrightness InGaN/AIGaN double-heterostructure bluelight-emitting diodes. Appl Phys Lett. 1994;64(13):16871689. doi:10.1046/j.1365-2842.1998.00336.x.

11. Shortall A, Harrington E. Temperature rise during polymerization of light activated resin composites. $J$ Oral Rehab. 1998;25:908-913. doi:10.1046/j.13652842.1998.00336.x.

12. Lloyd C, Joshi A, McGlynn E. Temperature rises produced by light sources and composites during curing. Dent Mater. 1986;2:170-174. doi:10.1016/s0109-5641(86)80030-6.

13. Yap AU, Soh MS. Thermal emission by different lightcuring units. Oper Dent. 2003;28:260-266.

14. Millen C, Ormond M, Richardson G, Santini A, Miletic V,
Kew P. A study of temperature rise in the pulp chamber during composite polymerization with different lightcuring units. J Contemp Dent Pract. 2007;8(7):29-37.

15. Ebenezar A, Anilkumar R, Indira R. Comparison of temperature rise in the pulp chamber with different light curing units: An in-vitro study. J Cons Dent. 2010;13(3):132135. doi:10.4103/0972-0707.71644.

16. Santini A, Watterson C, Miletic V. Temperature rise within the pulp chamber during composite resin polymerisation using three different light sources. Open Dent J. 2008;2:137141. doi:10.4103/0972-0707.71644.

17. Goodis H, White J, Andrews J, Watanabe LG. Measurement of temperature generated by visible-lightcure lamps in an in vitro model. Dent Mater. 1989;5:230234. doi:10.1016/0109-5641(89)90066-3.

18. Goodis H, White J, Gamm B, Watanabe L. Pulp chamber temperature changes with visible light-cured composites. In vitro study. Dent Mater. 1990;6(2):99-102. doi:10.1016/ s0109-5641(05)80038-7.

19. Kavitha M, Kailash S, Maheswari S. Thermographic analysis of temperature rise in the pulp chamber with LED and QTH light curing units: an in vitro investigation. SRM J Res Dent Sci. 2013;4(1):1-5. doi:10.4103/0976-433x.116820.

20. McCabe J. Cure performance of light-activated-composites by differential thermal analysis (DTA). Dent Mater J. 1985;1:231-234. doi:10.1016/s0109-5641(85)80048-8. 